\title{
Hands-on Practical Experience of Measurement and Analysis of Voltage and Current Harmonic Distortions for Educational Purposes
}

\author{
Seflahir Dinata ${ }^{1}$, Syaiful Bakhri ${ }^{2}$, Jana Dwi Haryati ${ }^{3}$ \\ Electrical Department, University of Pamulang, \\ dosen01138@unpam.ac.id ${ }^{1}$, dosen00047@unpam.ac.id²,janadwi89@gmail.com³
}

\begin{abstract}
To improve the quality of learning at the University of Pamulang, especially in the Department of Electrical Engineering, experiences are provided to the practice of power quality research using the Power Quality Analyzer tool. With this practice, it is expected that students can gain a deeper understanding of power quality problems. This paper discusses practical examples of research conducted regarding power quality problems due to harmonic distortions. The quality of power in an electric power system is affected by the parameters of power losses. One of them is a high level of harmonics. Nonlinear loads influence the harmonic. With the widespread use of nonlinear loads, this sinusoidal wave can be distorted. To find out how much the harmonics distort the load, the measurement of power quality is necessary. The quality of power in Pamulang University Building A has not been measured. This research was conducted to measure the harmonic voltage and harmonic load current of Pamulang University Building A using Power Quality Analyzer Metrel Power Plus MI 2792. The power quality is still in the healthy category because the total burden of electricity usage plus power losses is still far below the rating. It was found that the results are still in the healthy category because a total load of electricity usage plus power losses in Pamulang University is still far below the rating. Overall, the hands-on experience of the student to conduct a practical assessment of the power quality investigation can be a solution to improve their capacity building as well as preparing their competency.
\end{abstract}

Keywords: Harmonik, THD (Total Harmonic Distortion), IHD (Individual Harmonic Distortion), TDD (Total Demand Distortion), Power Quality, Education

\section{Introduction}

A power quality assessment in an electric power system needs to be monitored because it is closely related to taking corrective actions or the maintenance process of equipment so that the equipment has a longer lifetime. Monitoring an electric power system is very important because it can reduce costs and can avoid if there is interference with the system. The electric power quality system at Pamulang University Building (A), has never been measured, so to determine the quality of existing power in this building. Therefore, power quality measurements need to be carried out.

As in previous research in [1] the harmonic level of the transformer is essential on the performance of the transformer. High harmonics in a transformer will reduce the performance of the transformer, and power losses occur. In this study, voltage and current harmonic measurements employed Hioki 3169-20 Power Quality Analyzer measuring devices with full load on transformers BHT01 and BHT02 [1].

Based on this previous research, the writer will carry out harmonic measurements and 
analyzes on the load at Building A, Pamulang University Viktor Campus. The purpose of this study was to determine the magnitude of the harmonic values that occur at loads in Pamulang University Building A. The measurement methodology is carried out using the Power Quality Analyzer Metrel Power Plus MI 2792 tool.

\section{Theory}

\subsection{Power Quality}

Power quality is an assessment of quality problems related to voltage, current and frequency deviation that can result in the failure of an electrical equipment operation [3]. In these power quality problems, interference or deviation often occurs voltage variations, current and voltage imbalances, frequency variations, harmonic distortion and so forth.

In the electric power system, various types of interferences may occur and affect the quality of the power. The source of these disturbances usually come from interference originating from the applied unbalanced loads. Disturbances originating from consumer networks and devices are mainly caused by three-phase loads, the connection imbalances, the absence of appropriate neutral cables, the absence of earthing system, or the low circuit breaker rating. In these power quality problems, disturbances or deviations that often occur, including voltage variations, voltage and current imbalances, frequency variations, and harmonic distortions.

\subsection{Harmonics}

Harmonics are defined as a sinusoidal wave of high-frequency voltage or current, where the frequencies are multiple beyond the fundamental frequencies (50 Hz or $60 \mathrm{~Hz}$ frequency). The frequency values of the harmonic wave formed are the products of the fundamental frequency and the harmonic number ( $f, 2 f, 3 f$, and so on) [1]. If the fundamental frequency of an electric power system is $\mathrm{f0}(50 \mathrm{~Hz}$ or $60 \mathrm{~Hz})$ then the n-order Harmonic frequency is: $\mathrm{n} . \mathrm{f} 0$. In general, harmonics at a specific frequency order are described in percentages commonly called IHD (Individual Harmonic Distortion). Besides IHD, THD (Total Harmonic Distortion) is also used, which is a percentage value between total harmonic components and their fundamental components. Greater THD percentage causes a greater risk of equipment damage due to harmonics that occur in currents and voltages. For currents, THD sometimes cannot provide numbers that represent harmonic conditions, so TDD (Total Demand Distortion) units are usually used more often. In other words, TDD is distortions at the time of maximum current.

\subsection{Harmonic Index}

To analyse the effect of harmonics on the quality of voltage and current, it is determined by the harmonic index. Here are some of the meanings and equations contained in the harmonic analysis, namely:

a) Individual Harmonic Distortion (IHD), Individual Harmonic Distortion (IHD) is the percentage of harmonic values in a particular order [8].

b) Total Harmonic Distortion (THD), THD is the ratio between the total value of the harmonic component with the fundamental value and is usually expressed in percent (\%). The 
greater THD percentage causes the greater risk of equipment damage due to harmonics that occur in currents and voltages [8].

$$
\mathrm{THD}=\frac{\sqrt{I H D} 2^{2}+I H D 3^{2}+I H D 4^{2}+\ldots .}{\text { Fundamental }} \times 100 \%
$$

where :

THD : Total Harmonic Distortion

IHD : Individual Harmonic Distortion, if calculating THDV then IHD Voltage and if calculating THDI then IHD Ampere

c) Total Demand Distortion (TDD), The level of current distortion can be seen from the THD value, but it can be misinterpreted. A small current flow can have a high THD value, but does not pose a threat that can damage the electric power system so that the TDD (Total Demand Distortion) unit is usually used more often [8]. 


$$
\mathrm{TTD}=\frac{\sqrt{ } I 2^{2}+I 3^{2}+I 4^{2}}{I \text { demand }} \times 100 \%
$$

where :

$\begin{array}{ll}\text { TDD } & : \text { Total } \\ \text { Demand Distortion I } & : \text { Current } \\ \text { I demand } & : \text { Peak Load }\end{array}$

d) Harmonic and Voltage Standards

According to IEEE 519-2014 standards, Recommended Practices and Requirements for Harmonic Control in Electrical Power Systems are: Standar Harmonik

Table 1. The Limit Standar Of Voltage Harmonik IEEE 519-2014 [5]

\begin{tabular}{ccc}
\hline Bus Voltage V at PCC & Individual Harmonic (\%) & $\begin{array}{c}\text { Total Harmonic } \\
\text { Distortion THD (\%) }\end{array}$ \\
\hline $\mathrm{V} \leq 1.0 \mathrm{kV}$ & 5.0 & 8.0 \\
$1 \mathrm{kV}<\mathrm{V} \leq 69 \mathrm{kV}$ & 3.0 & 5.0 \\
$69 \mathrm{kV}<\mathrm{V} \leq 161 \mathrm{kV}$ & 1.5 & 2.5 \\
$161 \mathrm{kV}<\mathrm{V}$ & 1.0 & 1.5 \\
$\mathrm{~V} \leq 1.0 \mathrm{kV}$ & 5.0 & 8.0 \\
\hline
\end{tabular}

Table 2. Maximum harmonic current distortion in percent of IL Individual Harmonic Order (odd harmonics) ${ }^{\mathrm{a}, \mathrm{b}}$

\begin{tabular}{ccccccc}
\hline $\mathbf{I S C} / \mathbf{I L}$ & $\mathbf{3} \leq \mathbf{h}<\mathbf{1 1}$ & $\mathbf{1 1} \leq \mathbf{h}<\mathbf{1 7}$ & $\mathbf{1 7} \leq \mathbf{h}<\mathbf{2 3}$ & $\mathbf{2 3} \leq \mathbf{h}<\mathbf{3 5}$ & $\mathbf{3 5} \leq \mathbf{h} \leq \mathbf{5 0}$ & TDD \\
\hline$<20 \mathrm{c}$ & 4.0 & 2.0 & 1.5 & 0.6 & 0.3 & 5.0 \\
$20<50$ & 7.0 & 3.5 & 2.5 & 1.0 & 0.5 & 8.0 \\
$50<100$ & 10.0 & 4.5 & 4.0 & 1.5 & 0.7 & 12.0 \\
$100<1000$ & 12.0 & 5.5 & 5.0 & 2.0 & 1.0 & 15.0 \\
$>1000$ & 15.0 & 7.0 & 6.0 & 2.5 & 1.4 & 20.0 \\
\hline
\end{tabular}

${ }^{\mathrm{a}}$ Even harmonics are limited to $25 \%$ of the odd harmonic limits above.

${ }^{\mathrm{b}}$ Current distortions that result in a dc offset, e.g. half-wave converters, are not allowed.

${ }^{c}$ All power generation equipment is limited to these values of current distortion, regardless of actual ISC/IL where :

ISC : maximum short-circuit current at PCC

IL : maximum demand load current (fundamental frequency component) at the PCC under normal load operating conditions

\section{Metodology}

\subsection{Research Stage}

In this stage of the study, the author begins by conducting the survey of location that will be measured and collect supporting data such as Unpam's Single Line Diagram (SLD). At the time of conducting the survey also reassured for the distribution system at Unpam to the accompanying technicians whether it was appropriate in order to facilitate the data collection 
process. After that, data collection or measurement is carried out using the Power Quality Analyzer Metrel Power Plus MI 2792 tool at predetermined points. At the time of data acquisition, re-ascertain whether the data taken is appropriate, if the data is not appropriate, then the data retrieval is done than followed by a report writing. In reporting the results, the discussion is only limited to the results of measurements of voltage harmonics and current harmonics. After the obtained harmonic results are analyzed, then conclusions are drawn whether the harmonic values obtained are still in accordance with the specified standards or not.

\subsection{Tools and Materials}

In measuring and analyzing the harmonic distortion level at Unpam, the author will use several tools and materials, including the following:

a) Power quality analyzer Metrel Power Plus MI 2792 and accessories

b) Lenovo E470 Laptop

c) Software Power View V3.0

d) Single Line Diagram of Pamulang University

\subsection{Stages of Measurement and Data Retrieval}

At this stage of measurement and data retrieval, the authors determine the data collection points, in building A University Pamulang in accordance with the manual book from Metrel MI 2792 [7].

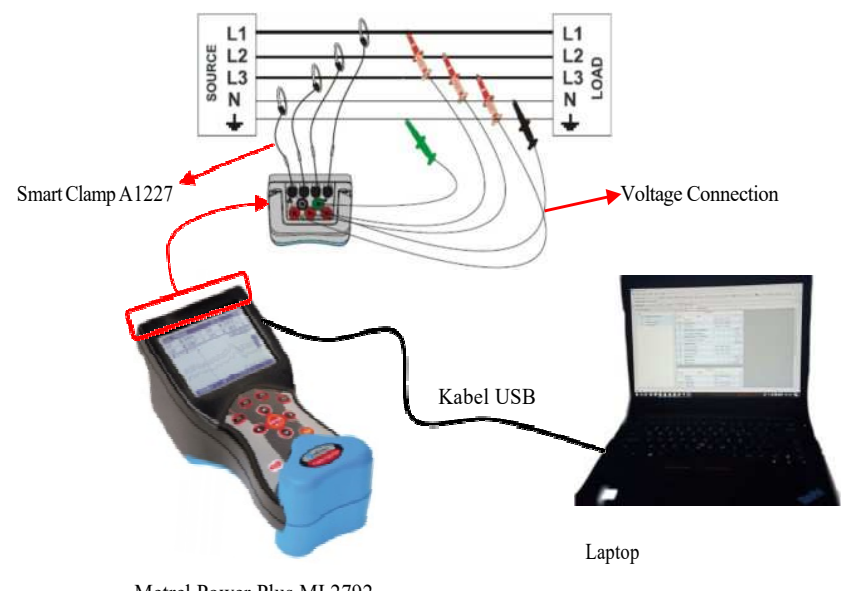

Metrel Power Plus MI 2792

Fig.1. Data Collection Process 


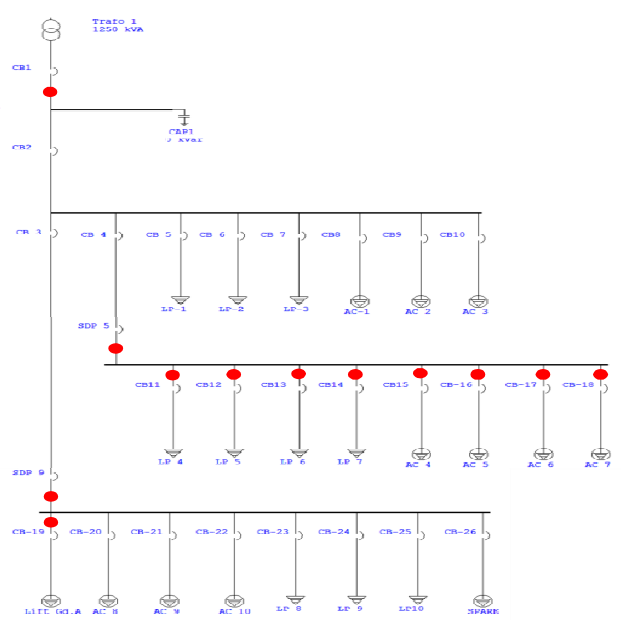

Fig.2. Power Quality Data Collection Points

\section{Results and Discussions}

\subsection{Summary of Voltage Harmonic Value}

Table 3. Summary Of Voltage Harmonic Value

\begin{tabular}{|c|c|c|c|c|c|c|}
\hline \multirow{2}{*}{ No } & \multirow{2}{*}{ Point of Measurements } & \multirow{2}{*}{$\begin{array}{c}\text { Standard } \\
\text { of THDv } \\
(\%)\end{array}$} & \multicolumn{3}{|c|}{ Measured THDv (\%) } & \multirow{2}{*}{ Status } \\
\hline & & & $\mathbf{R}$ & $\mathbf{S}$ & $\mathbf{T}$ & \\
\hline 1. & Outgoing Trafo building A & 8 & 2.0 & 1.9 & 2.1 & Passed \\
\hline 2. & SDP Floor 5 & 8 & 2.0 & 1.6 & 2.0 & Passed \\
\hline 3. & SDP Floor 9 & 8 & 2.0 & 1.6 & 2.0 & Passed \\
\hline 4. & Load for AC Floor 4 & 8 & 1.9 & 1.4 & 1.9 & Passed \\
\hline 5. & Load for AC Floor 5 & 8 & 1.9 & 1.5 & 1.9 & Passed \\
\hline 6. & Load for AC Floor 6 & 8 & 2.0 & 1.5 & 2.1 & Passed \\
\hline 7. & Load for AC Floor 7 & 8 & 2.0 & 1.5 & 2.0 & Passed \\
\hline 8. & Load for Lamp Floor 4 & 8 & 1.9 & 1.5 & 1.9 & Passed \\
\hline 9. & Load for Lamp Lantai 5 & 8 & 1.9 & 1.5 & 2.0 & Passed \\
\hline 10. & Load for Lamp Lantai 6 & 8 & 1.9 & 1.6 & 1.9 & Passed \\
\hline 11. & Load for Lamp Lantai 7 & 8 & 1.9 & 1.5 & 2.0 & Passed \\
\hline 12. & Load at Lift Gedung A & 8 & 2.1 & 1.6 & 2.0 & Passed \\
\hline
\end{tabular}




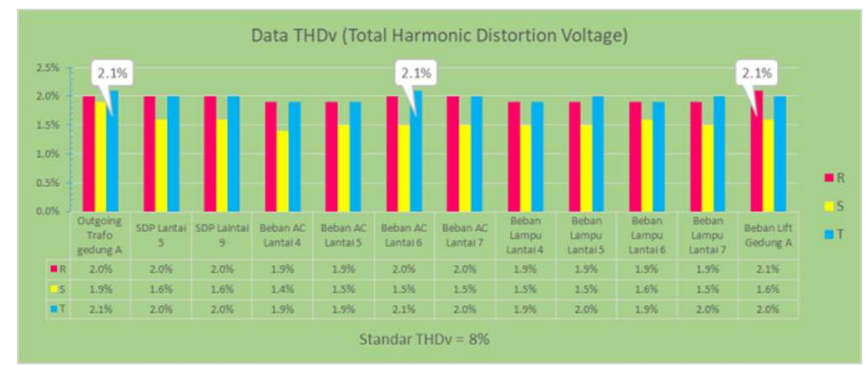

Fig.3. Data of THDv (Total Harmonic Distortion)

From the measurement results, THDv values at all measurement points are still included in the IEEE 519-2014 standard, with the highest value of $2.1 \%$ in the Outgoing $\mathrm{T}$ transformer phase of A building, T phase of 6 th floor AC load and phase $\mathrm{R}$ of elevator load A.

Table 4. Summary Of Current Harmonic Values

\begin{tabular}{llccccc}
\hline & & Standard & \multicolumn{3}{c}{ Measured THDv (\%) } & \\
\cline { 4 - 6 } No & Point of Measurements & of THDv & Status \\
\cline { 4 - 6 } & & $<15)$ & $\mathbf{R}$ & $\mathbf{S}$ & $\mathbf{T}$ & \\
\hline 1. & Outgoing Trafo building A & $<12.00$ & 8.334 & 6.014 & 7.224 & Passed \\
2. & SDP Floor 5 & $<15.00$ & 57.53 & 63.41 & 61.16 & Fail \\
3. & SDP Floor 9 & $<12.00$ & 9.504 & 8.044 & 10.598 & Passed \\
4. & Load for AC Floor 4 & $<12.00$ & 10.118 & 8.175 & 10.197 & Passed \\
5. & Load for AC Floor 5 & $<15.00$ & 9.421 & 6.953 & 8.903 & Passed \\
6. & Load for AC Floor 6 & $<12.00$ & 9.590 & 7.516 & 8.319 & Passed \\
7. & Load for AC Floor 7 & $<15.00$ & 53.034 & 43.599 & 55.459 & Fail \\
8. & Load for Lamp Floor 4 & $<15.00$ & 43.609 & 41.709 & 39.178 & Fail \\
9. & Load for Lamp Lantai 5 & $<15.00$ & 37.729 & 44.915 & 32.645 & Fail \\
10. & Load for Lamp Lantai 6 & $<15.00$ & 45.455 & 17.176 & 19.064 & Fail \\
11. & Load for Lamp Lantai 7 & $<15.00$ & 60.39 & 64.27 & 66.53 & Fail \\
12. & Load at Lift Gedung A & $<$ & & & & \\
\hline
\end{tabular}

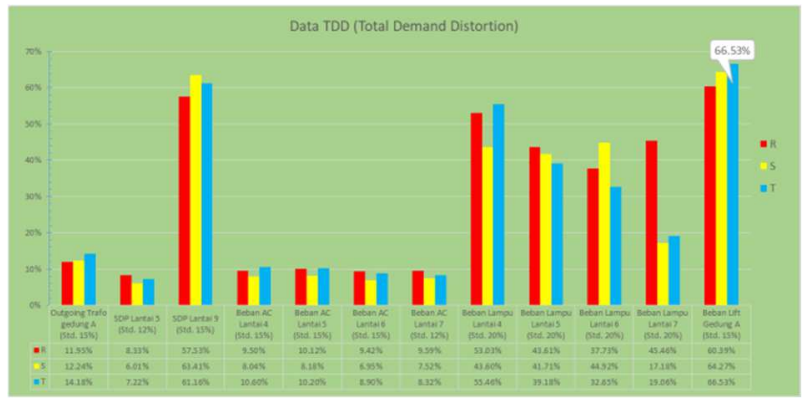

Fig.4. Data TDD (Total Demand Distortion

Based on the IEEE 519-2014 standard, the highest TDD value in the T phase of the Building A elevator load of $66.53 \%$ is out of bounds. However, the TDD value is still in the healthy category because the total measured load usage (the sum of peak loads and power losses) is still small because it is still far below the rating of $114.90 \mathrm{~A}(57.16 \%)$ of the circuit 
breaker rating of $100 \mathrm{~A}$.

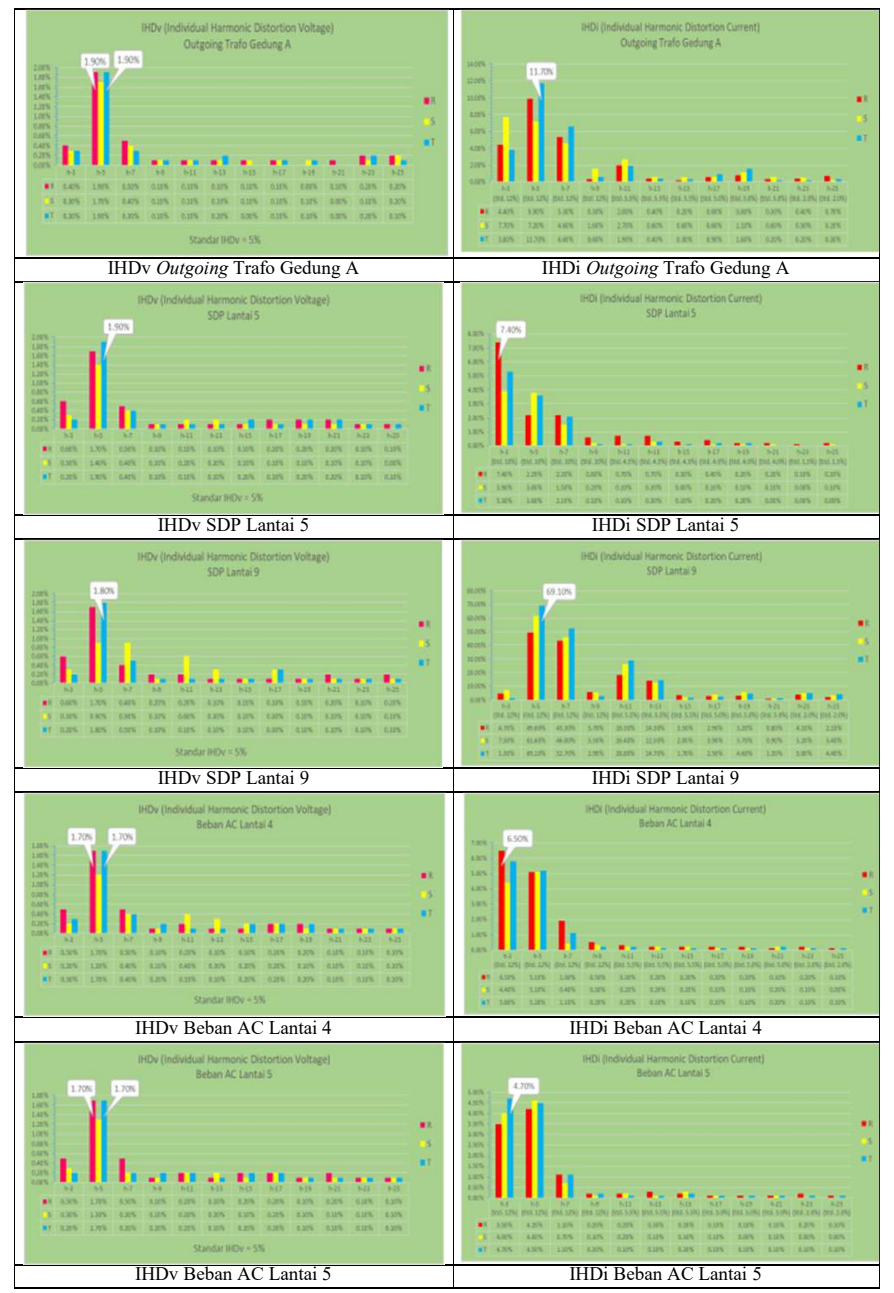

Fig. 5. The Individual Data of Harmonics

Table 5. Calculation Of Losses Due To High Current Harmonics

\begin{tabular}{ccccccccc}
\hline \multicolumn{1}{c}{$\begin{array}{c}\text { Point of } \\
\text { No }\end{array}$} & $\begin{array}{c}\text { CB } \\
\text { Rating TDD(\%) } \\
\text { (A) }\end{array}$ & & & & & & & \multicolumn{2}{c}{$\begin{array}{c}\text { Sum of } \\
\text { Load } \\
\text { (\%) }\end{array}$} \\
\hline 1. & SDP floor 9 & 630 & 63.41 & 36.21 & 62.79 & 44.40 & 2.92 & 9.97 \\
2. & Load for Lamp Floor 4 & 100 & 55.459 & 3.84 & 11.43 & 8.08 & 3.35 & 11.43 \\
3. & Load for Lamp Lantai 5 & 100 & 43.609 & 3.51 & 11.07 & 7.83 & 3.24 & 11.07 \\
4. & Load for Lamp Lantai 6 & 100 & 44.915 & 3.21 & 8.28 & 5.85 & 2.43 & 8.28 \\
5. & Load for Lamp Lantai 7 & 100 & 45.455 & 1.68 & 14.13 & 9.99 & 4.14 & 14.13 \\
6. & Load at Lift Gedung A & 250 & 66.53 & 61.41 & 97.11 & 68.67 & 11.38 & 38.84 \\
\hline
\end{tabular}




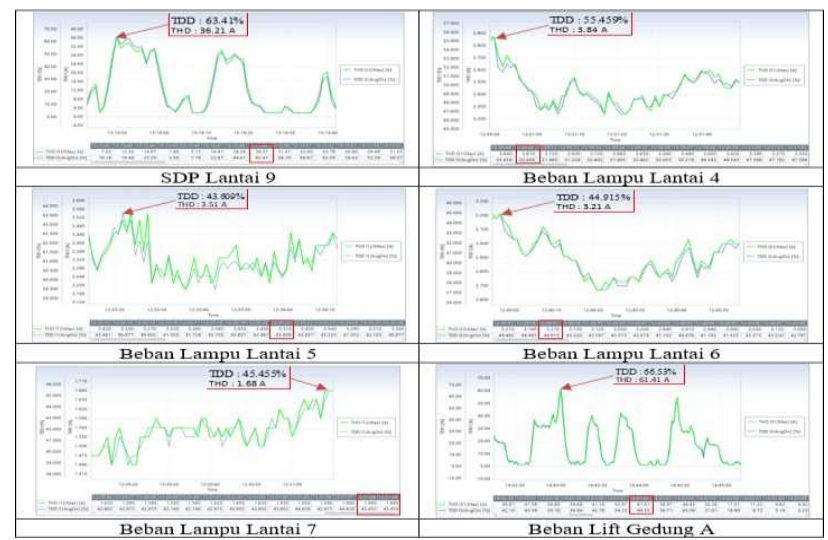

Fig. 6. The highest TDD graphic that exceeds the IEEE 519-2014 standard

Based on the calculation of the current harmonic values and power losses that occur in these loads caused by nonlinear loads in this case in the form of AC (Air Conditioner), LED lights, laptops and others. These nonlinear loads contribute significantly to the current harmonics due to the loads that work by switching.

As in the power losses table due to high harmonic values, they operate with a measured total load usage (the sum of peak loads and power losses) is still low and in the healthy category because it is still far below the rating of each of these loads. So, when reviewed from the safety side, the total use of the load is still in the safe categories. When it is viewed from the efficiency side there are still additional power losses due to significant current harmonics on each load.

In the assessment of voltage harmonics under the load of Pamulang University Building A, the measured harmonic value is still included in the IEEE 519-2014 standard, so that it does not require monitoring or further corrective action. In the measurement of current harmonic at the load of Building A University of Pamulang, there are still some values of total harmonic current (TDD) that are measured far above the standard that has been determined, among others, on the load of SDP Floor 9 (63.41\%), floor lamp load 4 (55.459\%), floor lamp load 5 $(43,609 \%)$, floor lamp load $6(44,915 \%)$, floor lamp load $7(45,455 \%)$, and building A elevator load $(66.53 \%)$. The results are still in the normal category because the total usage burden plus power losses due to harmonic values are still far below the rating, namely for the addition of losses due to harmonics on SDP Floor 9 (2.92\% of the 630A rating), floor lamp load $4(3.35 \%$ of rating $100 \mathrm{~A})$, floor lamp load $5(3.24 \%$ of rating $100 \mathrm{~A})$, floor lamp load 6 $(2.43 \%$ of rating $100 \mathrm{~A})$, floor lamp load 7 (4.14\% of rating $100 \mathrm{~A})$, and elevator building load A $(11.38 \%$ of rating $250 \mathrm{~A})$.

\section{Conclusion}

It can be concluded from the safety aspect review, the total use of the load is still in the safe category, only when it was investigated from the efficiency side there are still additional power losses due to significant current harmonics on each load. To reduce high current harmonics, the harmonic filters can be installed on the load sides. Overall, the quality of power 
in the load of Pamulang University Building A is still categorized under normal conditions.

\section{References}

[1] Koes Indrakoesoema, Yayan Andryanto, "Analysis of the Effects of Harmonics on Transformers (in Indonesia)," Prosiding Seminar Nasional Teknologi dan Aplikasi Reaktor Nuklir, p. 45.

[2] A. W. L. J. D. A. Djodi Antono, " Harmonics Of Current And Voltage In The Electricity Network Due To The Imposition Of Air Condition (AC) Three Phase Inverter (in Indonesia)," ReTII, 2015, p. 515.

[3] H. M. E.-E. FATHI, "Power Quality Assessment," Faculty Of Engineering Al-Azhar University, Cairo, Egypt, 2012.

[4] Z. J. Jiansheng Huang, "Power Quality Assessment of Different Load Categories," 2017.

[5] IEEE Standard Association, IEEE Std 519 ${ }^{\mathrm{TM}}-2014$ Recommended Practice and Requirements for Harmonic Control in Electric Power Systems, New York, USA: IEEE Standard Association, 2014.

[6] METREL, Instruction Manual Power Q4 and Power Q4 PlusMI 2592 and MI 2792, Slovenia: METREL d.d, 2011.

[7] Eko Supriyadi, PT. Technodrives, "Procedure Power \& Harmonic Measurement," vol. Rev.00, no. 02 May 2016, p. 10, 2016.

[8] PT. Technodrives, "Measurement of Power Quality Power House PT. Frisian Flag Plant Pasar Rebo," Jakarta, 2016. 